\title{
An analysis of geographic and product diversification in crop planning strategy
}

\author{
G. Villa ${ }^{a}$, B. Adenso-Díaz ${ }^{\text {bb }}$ and S. Lozano ${ }^{a}$ \\ ${ }^{a}$ Department of Industrial Management, University of Seville, Spain \\ \{gvilla; slozano\}@us.es

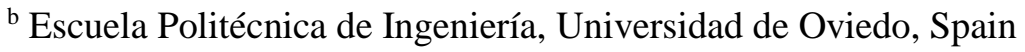 \\ adenso@uniovi.es \\ * Corresponding author: \\ Postal address: $\quad$ Escuela Politécnica de Ingeniería, Campus de Viesques \\ 33204, Gijón, Spain \\ E-mail: $\quad$ adenso@uniovi.es $\quad$ Phone: +34985181962
}

\section{ARTÍCULO PUBLICADO EN LA REVISTA}

Agricultural Systems (2019), 174, 117-124

doi: https://doi.org/10.1016/j.agsy.2019.05.006

\begin{abstract}
An empirical study of the factors that influence the optimal degree of geographic and product diversification to use as a risk mitigant in agriculture planning is carried out using a simple crop planning optimisation model that maximises the expected profit. The factors considered include the distance between the available plots, the amount and variability of spoilage risk, the yield variability and the variance in the produce selling prices. We propose a new metric, based on the entropy concept, for quantifying the geographic diversification. The degree of geographic and product diversification of the optimal plan, as well as the profit level, the overall percentage of demand satisfied and the number of plots unused, are studied. The results show that the optimal combination of the two types of diversification (geographic and product) are dependent on the specific scenario considered, and the factor that has the largest influence on the degree of geographic and product diversification is the separation between the plots. A similar effect is in the variance of the selling prices. Also, as the geographic diversification of the optimal solution increases so does its product diversification and its profit level. The profit level decreases significantly as the separation between the plots and the average
\end{abstract}


spoilage risk increases. Other effects that are worth mentioning are the reduction in the percentage of demand satisfied as the separation between the plots increases, and when the variance in the selling prices increases.

Keywords: Agriculture; crop planning; risk mitigation; geographic diversification; product diversification

\section{INTRODUCTION}

Agriculture is an economic sector with significant risks, when compared to industry or services. Different types of risks in agricultural activities can be considered (Nikolova and Linkova, 2011). Some of them are related to the market in which the product is sold, including exogenous factors (possibly generated by events in other countries) that may affect the price of seeds and produce due to the instability of agriculture markets, fluctuations in the cost of the resources used, such as labour, machinery, currency rates and interest rates. All of them can severely affect the profitability of the agricultural activity. Other risks are institutional, including production restrictions, export limitation, or taxes, which can also change the expected outcomes of the business plan. There are other risks related to the high dependence of crop yields on the climate as, more and more frequently, there are heavy rains, droughts, hail and extreme temperatures. And, finally, there is the risk of diseases, insect plagues, wildfires, etc. In these latter cases, the problems are usually located in a specific area and affect only farms in that location.

To mitigate those risks, which overall make it very hard to forecast the expected losses, there are some strategies that could be used. The most traditional is risk insurance. However, the systemic risk of agricultural yield (it is estimated that in the US, the portfolio risk of crop insurance is ten times the average risk of general industry, Feng and Hayes, 2016) makes it difficult for the development of private crop insurance markets, thus requiring government subsidies to support the insurance programmes. The use of some financial tools via hedging or options could also be useful, spreading the risk over time.

Finally, another alternative frequently used in investment is to spread the risks among different objects, i.e. diversification, expecting that while some of them could fail, others would be successful, thus reducing the global variance of the venture. Different 
studies (Tadesse and Blank, 2003; Ogundari, 2013, etc.) show that, among the above alternatives, diversification is clearly the preferred option for farmers around the world, for its simplicity and effectiveness.

The most traditional way of diversifying in agriculture is to sow different crops (product diversification). By doing so, in case selling prices evolve unexpectedly, which is likely for some of the selected crops, the higher revenues from some products could compensate for the losses in other commodities. A second clear alternative is to sow one commodity in different parcels of land (geographic diversification), in which case, if one plot is affected by a pest, localised storms or extreme weather, it is possible that the others will not to be affected and thus part of the harvest may be saved.

Many authors have studied these two strategies, and their implementation in different parts of the world (Krueger et al., 2002; Morrison Paul and Nehring, 2005; Ogundari, 2013; Pacin and Oesterheld, 2014; Djokoto et al., 2017). In most cases, they have shown their effectiveness, and studied their relationship with other socio-economic factors, explaining how these factors have an influence on the selection of either of these two strategies.

In this paper we analyse not the socio-economic factors affecting the most convenient strategy for diversifying risks as some authors have, but the economic factors (distance between the parcels of land, price variability, spoilage rate, etc.) that could make it more interesting to use one type of diversification or another. By simulating a high number of scenarios with different values in these factors, and looking for the most efficient way to define a cropping plan (using a linear programming optimisation model), we can analyse the diversification level for all those experiments, and check whether those factors have an influence on the optimal production plan. The goal is to better understand which economic factors have an influence on the best cropping plan and on its level of diversification.

\subsection{Diversification strategies}

There are three main diversification strategies in agriculture (Tadesse and Blank, 2003). The first is crop or product diversification, a practice derived from portfolio theory in 
finance. The aim is to reduce variance in sales revenues, by selling more than one product. It is easily implemented by any grower with the expertise to sow more than one commodity, selecting those crops with non-positive correlation among their selling prices, and benefiting from economies of scope. Genetic improvements have made it easier for farmers to find convenient seeds to be used to diversify production in regions where those crops were not common.

Mono-cultural practices are perhaps more efficient from the point of view of expertise and know-how exploitation, taking advantage of economies of scale. But any disease affecting a specific crop could mean the bankruptcy of the farm, making it less robust from an economic and ecological point of view. Therefore, the practice of crop diversification has attracted the attention of farmers around the world, not only for reducing uncertainty, but also as a tool to reduce diseases, to increase soil fertility (Nkurunziza et al., 2017) and to generate income and employment, i.e., because of its many economic, social and agronomic benefits (Djokoto et al., 2017). It plays as well an important role to increase resilience of agroecosystems and maintain diversity, integrating diverse cultivars, crops and intercrops (Wezel et al., 2014).

Schroth and Ruf (2014) published a review, analysing the factors affecting this type of diversification, concluding that the age (although being younger is not always a driver), education and family size have influence in the decision. They consider this practice a sort of self-insurance that makes farms more resilient to climate change. In addition, farmers increase their food security, and spread their income to periods between the harvests of their traditional produce.

However, there are also some downsides. The farmer incurs additional opportunity costs sowing not the most profitable crop, reducing economies of scale, and requiring an extra effort to market small quantities of the new produces. Also, diversified farms suffer from more complex management systems (Navarrete et al., 2015). In this line, Meynard at al. (2018) analyse the case of France finding that although traditionally the major modernisation movement was towards specialisation looking for economies of scale, that implied tensions on water, increase in greenhouse emissions and use of pesticide, and a reduction in biodiversity. Crop diversification could help to sort that out, but to 
succeed it is necessary that all the stakeholders along the value chain collaborate and mobilise to work in this new and more complex environment.

Many cases of this practice around the world have been reported in literature. Ogundari (2013), for example, confirmed the importance of the implementation of this strategy in Nigeria, identifying it as one of the factors affecting the technical efficiency of farms in the country, together with peasants' education and extension of the parcels of land. In India, Ali (2015) found that age, education, income and landholding size have all influenced the choice of diversification strategies. However, Djokoto et al. (2017) concluded that, in Ghana, age was not significant in deciding to diversify by product, but that marital status, total land endowment, and the cultivation of cocoa as the main product were.

A variant of the product diversification strategy is the diversification of activities (Nikolova and Linkova, 2011), i.e. introducing related productions that could take advantage of the resources and know-how available (for instance, developing organic products, or providing agricultural services, or even providing tourism service, Yang et al., 2018).

To analyse the level of product diversification in different scenarios, some authors have proposed different ways of measuring the implementation level of that strategy based on metrics taken from ecology and economics. Thus, Djoko et al. (2017), Ogunda (2013) and Shaxson and Tauer (1992) present the mathematics of different indices, such as the Herfindahl index, the Ogive index, the Simpson index, and different variants of entropy metrics. Most are based on considering for each item of produce the percentage of contribution to total production, and analysing that distribution, i.e., not only the number of commodities sown, but their contribution to global outcome. In particular, one of the most used metrics for measuring product diversification is the Shannon entropy index (Shannon and Weaver, 1949). If we call $\mathrm{p}_{i}$ the proportion of area of the total land considered to be assigned to produce $i$, this index is defined as the entropy $-\Sigma \mathrm{p}_{i} \ln \left(\mathrm{p}_{i}\right)$ of that distribution.

The second type of diversification is geographic diversification. Here the goal is to reduce yield variance, instead of variance in sales revenues (Tadesse and Blank, 2003). 
It is more difficult to implement as growers need to have at their disposal two or more parcels of land, distant geographically and with a non-positive correlation in their climate extremes in which to sow the commodity. Therefore, apparently only big farmers would be able to afford to implement this strategy. However, small farmers also are often forced to use this strategy as a result of the land fragmentation, which is widespread due to political and sociological factors (Latruffe and Piet, 2014).

Different authors have studied the benefits of implementing this strategy, with contradictory results. Lu et al. (2018) consider that only in case of low costs is this strategy reasonable. As costs increase, expanding the area of each plot and reducing the number of plots can lead to economies of scale, thus compensating its negative influence on yields. However, Latruffe and Piet (2014) claim that although it is harmful for farm performance overall, there are other benefits associated with land fragmentation, mainly related to the reduction of production risk and the increased biodiversity due to better matches between crops and soil.

One of the first papers to study this strategy was by Nartea and Barry (1994), who claim that it is important to understand this type of diversification, because its benefits would include the reduction in crop insurance premiums, more credit availability for farmers and an increase in the rents obtained. They note that although the variance of returns decreases, it must be taken into account that there are new costs to be introduced in the equation (transportation, monitoring, yield loss due to delays, idle resources). They consider three factors in their experiments based on Central Illinois data: farm size, number of tracts, and dispersion of tracts (with distances between 8 and 13 miles), always with the headquarters in the geographic centre. They conclude that only for groups of farmers forming a cooperative could this diversification be effective, given the increase of costs observed in their experiments. Regarding distance (which clearly increases cost), Davis et al. (1997) found in their study that to obtain a reduction of $30 \%$ in yield variation using this diversification, the distance between the orchards needs to be between 4.83 miles and 72.50 miles, depending on the number of orchards owned by the grower.

Krueger et al. (2002) compare geographic diversification of table grapes, with production in California alone, finding that extending production in different climate 
zones, results in being more profitable and helps in crossing international borders. Larsen et al. (2015), using finance theory, developed a Monte-Carlo simulation model to evaluate this type of diversification, considering three separate locations in Kansas, Texas and North Dakota, assigning acreage to each farm. The results support the benefits of spreading crops but without considering all the costs involved.

Regarding existing metrics to measure its level of implementation, some authors consider Simpson's index $\mathrm{S}=1-\left(\sum \mathrm{a}_{\mathrm{i}}^{2} /\left(\sum \mathrm{a}_{\mathrm{i}}\right)^{2}\right)$ used for product diversification, but in this case $a_{i}$ is the area of each plot $i=1$..N instead of the value of each produce $i=1$..P (Ciaian et al., 2018; Lu et al., 2018). However, this index cannot capture all the complexity of land fragmentation, that includes not only the number and plot size, but also the shape of plots, the distance to farm building or the plot scattering (Latruffe and Piet 2014). Given the difficulty of including all those factors in a simple metric, in this paper a new metric based on the entropy of crop planning spread will be used.

Finally, a third diversification possibility considered by Tadesse and Blank (2003) is to implement cultivar diversity, which tries to capture the advantages of the two previous strategies. By selecting cultivars of one produce uncorrelated in their growing schedules, the harvest can be collected in different periods of time, reducing yield variance, by reducing exposure to climate extremes, and improving sales revenues by accessing different season markets. Weeks et al. (2016) study the risk and profitability of this strategy in the case of soybeans.

Note that although there can be different drivers of diversification (food security, soil fertility increase, job creation, etc.) here we are mainly focusing on risk minimisation. This is one of the strongest advantages of using geographical diversification and product diversification, and here we are going to compare the contribution of these two strategies when the goal is to search for the best crop plans (i.e. with maximum profit).

Ciaian et al. (2018) studied the relationship between product and geographic diversification in the specific case of Albania, a country with a high land fragmentation after the land privatization of 1991. Measuring both diversification strategies using Simpson's index and using a linear regression model, they observed that product 
diversification increases with the land fragmentation. The drivers of such behaviour seemed to be efficiency motives (allocating land to its best use) and the need of selfconsumption.

It seems interesting to study how optimizing crop plans could affect the implementation of both strategies. However, from the literature review carried out, it appears that no study has tried to identify which factors have an influence on the degree of utilisation of each of the two diversification strategies. Hence, in this paper, we carry out an empirical study in which a number of scenarios are considered with different combinations of selected experimental factors. For each scenario the optimal cropping plan is determined using a simple optimisation model, and the extent to which this optimal solution uses product and geographic diversification; also other relevant characteristics of the solution, are analysed and related to the factors considered.

\section{EXPERIMENTAL SETUP}

For testing to what extent the optimal crop plan is affected by the characteristics of the farming scenario, an experimental framework was designed. It includes five potential products to be harvested, and a reticular layout of the potential farms (plots), with the central facilities (deposit of all required machinery and warehousing for the collection of all the harvested products) located in the grid centre - a configuration similar to the one used by Nartea and Barry (1994) in their research. This structure with 24 potential plots seems quite general for our purposes (see Figure 1).

Regarding the factors that are likely to affect the diversification strategies in any specific scenario, first, the distance between the potential plots seems to be a relevant variable, as indicated by previous works (e.g. Davis et al., 1997), since the farther the potential locations, the higher the transportation costs due to geographic diversification. This distance factor (F1) will thus have two levels: low level, corresponding to a 
separation of $15 \mathrm{~km}$ between two adjacent plots in the grid (same distance used in Nartea and Barry, 1994) and high level (separation of 30km).

As mentioned in section 2, a variable that makes geographic diversification more attractive is the likelihood of any farm experiencing problems and a percentage of the produce then being spoilt. Therefore, the likelihood of harvest failure must be captured in our scenarios. We divided that probability into two factors: F2 will consider the general level of spoilage in all the plots (low level corresponds to an average expected loss of $10 \%$ of harvest in all farms, and high level corresponds to an average loss of $20 \%$ ), while factor F3 will capture the variability of spoilage probability among all the plots (in the low level, it will randomly assign an expected percentage of spoilage to each farm $k, \pi_{k}$, in the interval F2 $\pm 5 \%$, while in the high level the interval will be F2 $\pm 15 \%)$.

In the real world, not all the plots are expected to have the same yield, and for that reason a factor F4 is introduced, randomly assigning a yield for product $i$ at plot $k, \rho_{\mathrm{ik}}$, with a low level corresponding to a yield of $\pm 10 \%$ around the average yield and a high level of $\pm 25 \%$ around the average yield).

Finally, as the interest of diversifying products is due to the prices of the different cropping alternatives, a factor F5 is included, capturing the price $p_{i}$ of produce $i$ computed as $p_{i}=p^{\prime} \times(1+\mathrm{U}[0 ; \mathrm{F} 5])$ where $\mathrm{U}[0 ; \mathrm{F} 5]$ is a random variable uniformly distributed between 0 and F5 and $p$ ' is a base price level for all the produces (low level of factor F5=1.1; high level of factor F5=1.5).

For each of the $2^{5}$ treatments in this experiment, 32 replications were generated, and each of the 1024 instances were solved using the linear programming optimisation model described below. 


\subsection{Crop planning model}

$\underline{\text { Let }}$

\section{$\underline{\text { Instance data }}$}

$\mathbf{K} \quad$ set of plots, $\mathbf{K}=\{1 \ldots 24\}$

I $\quad$ set of produces, $\mathbf{I}=\{1 \ldots \mathrm{P}\} .(\mathrm{P}=5)$

$\mathrm{D}_{i} \quad$ potential demand of produce $i$.

A area of each plot, $\mathrm{m}^{2}$.

$\mathrm{d}_{\mathrm{k}} \quad$ distance from plot $\mathrm{k}$ to the central deposit (depends on the plot separation factor F1).

$\rho_{\mathrm{ik}} \quad$ yield of produce $i$ in plot $k$ (depends on $\mathrm{F} 4$ ).

$\pi_{\mathrm{k}} \quad$ mean harvest spoilage in plot $k$ (depends on factors F2 and F3).

$\mathrm{p}_{i} \quad$ unit selling price of produce $\mathrm{i}$ (depends on 54).

$\lambda_{\mathrm{i}} \quad \mathrm{kg}$ of seeds of $i$ needed to plant one $\mathrm{m}^{2}$

$\mathrm{m}_{\mathrm{k}} \quad$ machinery transportation cost per $\mathrm{km}$

$\mathrm{s}_{\mathrm{i}} \quad$ planting cost per $\mathrm{kg}$ of seed of produce $i$.

$\mathrm{r}_{\mathrm{i}} \quad$ manpower cost of harvesting per $\mathrm{kg}$ of produce $i$.

$\mathrm{t}_{\mathrm{k}} \quad$ transportation cost per $\mathrm{kg} \mathrm{km}$ of harvested products transported to the central deposit.

\section{$\underline{\text { Decision variables }}$}

$\mathrm{x}_{i k} \quad \%$ of plot $k$ planted with produce $i$ (continuous non-negative variable)

$\mathrm{y}_{k} \quad$ binary variable that when equal to one indicates that plot $k$ is planted (with any produce)

With those variables defined, we note that the expected amount of produce harvested can be evaluated as $\Sigma_{k} \mathrm{x}_{i k} \cdot \mathrm{A} \cdot \lambda_{i} \cdot \rho_{i k} \cdot\left(1-\pi_{k}\right)$, and therefore the objective function will 
consist of the income from selling that amount, minus the machinery transportation costs, planting costs, and harvesting manpower and transportation costs:

$\operatorname{Max}$

$$
\begin{array}{r}
\sum_{i} \mathrm{p}_{i}\left[\sum_{k} \mathrm{x}_{i k} \cdot \mathrm{A} \cdot \lambda_{i} \cdot \rho_{i k} \cdot\left(1-\pi_{k}\right)\right]-\left\{\sum_{k} \mathrm{~m}_{k} \cdot 2 \mathrm{~d}_{k} \cdot \mathrm{y}_{k}+\sum_{i} \mathrm{~s}_{i} \cdot\left[\sum_{k} \mathrm{x}_{i k} \cdot \mathrm{A} \cdot \lambda_{i}\right]+\right. \\
\left.\sum_{i} \mathrm{r}_{i} \cdot\left[\Sigma_{k} \mathrm{x}_{i k} \cdot \mathrm{A} \cdot \lambda_{i} \cdot \rho_{i k} \cdot\left(1-\pi_{k}\right)\right]+\sum_{k} \mathrm{t}_{k} \cdot 2 \mathrm{~d}_{k} \cdot\left[\sum_{i} \mathrm{x}_{i k} \cdot \mathrm{A} \cdot \lambda_{i} \cdot \rho_{i k} \cdot\left(1-\pi_{k}\right)\right]\right\}
\end{array}
$$

The constraints in this model only need to impose that the production of each produce should not be larger than its demand, and that the binary variables $\mathrm{y}_{k}$ are correctly related to the continuous variables $\mathrm{x}_{i k}$ :

$$
\begin{array}{ll}
\sum_{k} \mathrm{X}_{i k} \cdot \mathrm{A} \cdot \lambda_{i} \cdot \rho_{i k} \cdot\left(1-\pi_{k}\right) \leq \mathrm{D}_{i} \quad \forall i \\
\sum_{i} \mathrm{x}_{i k} \leq \mathrm{y}_{k} \quad \forall k \\
\mathrm{x}_{i k} \geq 0 \quad \forall i \forall k \quad \mathrm{y}_{k} \text { binary } \forall k
\end{array}
$$

\subsection{Response variables}

To evaluate the optimal crop plan found for each instance and assess the influence of the factors considered to define its parameters, some measures for the diversification levels need to be defined. As indicated in section 2, in the literature, only metrics to assess the product diversification have been defined. Among them, those based on the entropy of the distribution of the area sown with each crop are commonly used to measure how different the distribution of produce planted in each plot is. High entropy levels indicate high product diversification, while low levels mean that a few different crops are being used.

Given that the characteristics of our experimental framework consider five potential crops with their corresponding demands, and that our model will decide how many are the most profitable to consider, we will take into account not the distribution of the land area planted with each different product, as usually done in the literature, but the distribution of the percentage of the potential demand for the different types of produce that are covered by the crop plan. While constraint [2] guarantees that the expected production cannot exceed the potential demand, depending on the exploitation costs and 
selling prices, it is possible that not all the potential demand for all the produce will be covered. Therefore, the proposed measure of product diversification, PD, is related to the percentage of potential demand for each produce $i$ that is satisfied, $\Delta_{i}=\left(\sum_{k}\right.$ $\left.\mathrm{x}_{i k} \cdot \mathrm{A} \cdot \lambda_{i} \cdot \rho_{i k} \cdot\left(1-\pi_{k}\right)\right) / \mathrm{D}_{i}, \forall \mathrm{i}$. In an extreme case, if only one crop is planted, the product diversification is 0 , while if the demand for all five items of produce are equally satisfied, the plan has a high level of product diversification, giving a similar priority to satisfying the demand for all the potential produce. Denoting as $\Delta^{\prime}{ }_{i}$ the normalisation of those percentages of demand being satisfied (i.e., $\Sigma_{i} \Delta^{\prime}{ }_{i}=1$ ), we will define PD as the entropy of distribution $\Delta_{i}^{\prime}$, i.e., $\mathrm{PD}=-\sum_{\mathrm{i} \in \mathrm{I}} \Delta_{\mathrm{i}}^{\prime} \cdot \ln \Delta_{\mathrm{i}}^{\prime}$.

On the other hand, regarding the geographic diversification, GD, we will consider not only the number of plots used for planting each item of produce, but how diversified the amount planted in each one is. For instance, if $99 \%$ of the seeds of a specific crop are planted in one plot and only $1 \%$ in another, this is not really describing a high level of diversification. Moreover, when only one plot is used for one crop, the particular geographic diversification is 0 , while the maximum geographic diversification corresponds to the case in which all the plots used for one crop have the same area planted. Therefore, we define GD as the average, for the different crops $I$, of the entropy of the distribution $\Phi_{i k}$ of the amount produced of $i$ in plot $k$, i.e.

$$
\mathrm{GD}=\frac{1}{|\mathrm{I}|} \sum_{\mathrm{i} \in \mathrm{I}}\left(-\sum_{\mathrm{k} \in \mathrm{K}} \Phi_{\mathrm{ik}} \ln \left(\Phi_{\mathrm{ik}}\right)\right)
$$

where

$$
\Phi_{\mathrm{ik}}=\frac{\mathrm{x}_{\mathrm{ik}} \cdot \mathrm{A} \cdot \lambda_{\mathrm{i}} \cdot \rho_{\mathrm{ik}} \cdot\left(1-\pi_{\mathrm{k}}\right)}{\sum_{\mathrm{k}^{\prime} \in \mathrm{K}} \mathrm{x}_{\mathrm{ik}^{\prime}} \cdot \mathrm{A} \cdot \lambda_{\mathrm{i}} \cdot \rho_{\mathrm{ik}} \cdot\left(1-\pi_{\mathrm{k}^{\prime}}\right)} \quad \forall \mathrm{i}, \mathrm{k}
$$

To better understand which is the most convenient crop strategy in each case, some other characteristics of the optimal crop plans will be analysed as well, including:

- whether the considered factors have an influence on the percentage of demand satisfied, $\Delta=$ mean $\left(\Delta_{i}\right)$, and on the model objective function (i.e. expected profit) 
- whether the number of unused potential plots (let us call it the Number of Fallows) depends on the factors considered. Depending on the demand (or on the profitability of each crop), it may be more or less likely that some plots are not used to harvest any produce.

\section{RESULTS AND DISCUSSION}

Figure 2 shows the diversification metrics corresponding to the optimal solution of the 1024 different instances generated. For the Geographic Diversification response variable (GD), it seems that for the second half of instances that correspond to the high level of factor F1 (i.e., more distant plots), clearly the value of GD is lower, and a similar behaviour can be observed for the Product Diversification (PD) response variable.

To check whether the factors considered for the instance generation have influence on the selected metrics, Figure 3 shows the average value for each level of each factor. In general, it is observed that F1 (distance among plots) has a big influence on the mean values of the four response variables. As the farms are more spread, both GD and PD as well as the percentage of demand satisfied $\Delta$ have lower values, while the number of unused plots increases. Also, factor F5 (variability among the selling prices of the different produces) seems to be relevant for all the metrics, with lower values of GD, PD and demand covered when there are crops that are much more lucrative than others (the cheapest ones are not planted and their demand not served). The box-plots for factors F1 and F5 also indicate their influence, affecting the optimal cropping plans as regards their degree of diversification and demand satisfaction (Figure 4). To confirm the statistical significance of these results, and given the non-parametric nature of the data obtained, Wilcoxon rank-sum tests were run for F1 and F5 and for the four metrics considered. These tests showed that the distribution of the results is different depending on the level of each factor. An analysis of interactions did not show any interrelationship between F1 and F5 for any of the response variables. 
Therefore, the results show that as the separation among potential plots increases, the costs induced by transportation of harvest and machinery disincentive planting in distant plots thus concentrate on cropping of fewer plots (reduced GD). This decision to not plant in all plots reduces the overall production and hence average percentage of demand satisfied. The results also show that a larger separation also leads (in an optimum cropping plan) to a reduction in product diversification, i.e. a concentration on fewer crops, presumably those that are more profitable. Regarding F5, as the crops considered have more diverse unit selling prices, fewer crops are considered for planting, thus reducing the average demand satisfied and product diversification. It also reduces the number plots effectively used.

As regards the profit of the optimal cropping plans, it depends significantly only on factor F1 (distance between plots) and factor F2 (the overall percentage of spoilage at the farms). These two factors are therefore the most influential on the bottom line (according to our experimental framework), more than other factors such as the selling price of the produce. Figure 5 shows the box-plot of the optimal profit level for these two factors.

The relationships between the geographic diversification and the other response variables are shown in Figure 6. Thus, in the optimal cropping plan, as the geographic diversification increases, the product diversification $\left(\mathrm{R}^{2}=0.68\right)$, as well as the percentage of demand satisfied $\Delta\left(\mathrm{R}^{2}=0.80\right)$, also increase. Therefore, when the optimal decision uses geographical diversification it also uses product diversification as well. When more plots are used, it is more profitable to plant different crops than to concentrate on a single one. Regarding the profits, the highest values are obtained in the cases in which both geographic and product diversifications are used. However, this may not be a direct consequence of these strategies but of the mediating effect of the distance between the plots (factor F1): as the distance is smaller (low level of F1), the objective function takes higher values because transportation costs are reduced, and at the same 
time as commented above, for the low level of F1, the geographic diversification is significantly increased.

As a summary of the results, Table 1 shows, for each type of diversification, whether the average value for each level is above or below the average value for the whole factor. The arrows are larger for factors F1 and F5 because they are the most influential ones. Thus, as discussed above, for F1 (distance between plots) and F5 (variability of selling price of the produce), the behaviour of both diversification metrics is the same: for low distances and homogeneous selling prices, and the geographic and product diversifications are high, while they are low as distance increases and selling prices differ. The behaviour is different, however, for F2 (average spoilage) and F4 (plot yield). When the risk of spoilage is low, the geographic diversification is low, while the product diversification is high and the opposite when the spoilage level is high. As regards F4, when the yields of the plots are quite homogeneous (similar plots) geographic diversification is high while the product diversification is small and the opposite when the plots are heterogeneous in their yields. Finally, the effects of factor F3 (variability of spoilage risk) are similar to (although much less significant than) those of F1 and F5, i.e. low variability fosters geographic and product diversification, while high variability reduces both.

$=================$ TABLE 1

\section{CONCLUSIONS}

In this paper, an empirical study of the factors that influence the optimal degree of geographic and product diversification to use has been carried out. In particular, the factors considered include the distance between the available plots, the amount and variability of the spoilage risk, the yield variability and the variance in produce selling prices. For each combination of the level of these factors, several instances have been generated and solved using a simple crop planning optimisation model that maximises the expected profit. The degree of geographic and product diversification of the optimal plan thus computed has been measured using some entropy-based indexes. Three other 
response variables have been considered, namely the profit level, the overall percentage of demand satisfied and the number of potential plots unused.

The results show that the optimal combination of the two types of diversification (geographic and product) are dependent on the specific scenario considered and the factor that has the largest influence on the degree of geographic and product diversification is the distance between the plots. Thus, the closer the different plots, the larger both types of diversification. A similar effect is the variance in selling prices, i.e. the smaller the variance, the larger both types of diversification. The variability of the spoilage risk also has a similar effect. However, other factors have different effects. Thus, a high average spoilage risk increases geographic diversification but reduces product diversification, while a high yield variability increases product diversification and reduces geographic diversification.

It has also been observed that as the geographic diversification of the optimal solution increases so does its product diversification and profit level. The profit level decreases significantly as the distance between the plots increases (undoubtedly due to an increase in transportation costs) and also when the average spoilage risk increases. Other effects that are worth mentioning are the reduction in the percentage of demand satisfied as the distance between the plots increases and when the variance in the selling prices increases. Further research could focus on the development of more specific and detailed optimisation models that could define pure strategies of diversification instead of mixed strategies, as in our case. Also, more levels in the experiments (mainly when discussing the factor distance) could facilitate the measurement of the outputs, namely how distance affects diversification more accurately.

\section{Acknowledgements}

This research was carried out with the financial support of the Spanish Ministry of Economy, Industry and Competitiveness, and the European Regional Development Fund (ERDF), grant DPI2017-85343-P; and by Red Iberoamericana de Agro- Big Data y Bigdssagro (CYTED, 516RT0513). 


\section{REFERENCES}

Ali, J. (2015) "Adoption of Diversification for Risk Management in Vegetable Cultivation”, International Journal of Vegetable Science, 21, 1, 9-20.

Ciaian, P.; Guri, F.; Rajcaniova, M.; Drabik, D.; Paloma, S.G.Y. (2018) "Land fragmentation and production diversification: A case study from rural Albania". Land Use Policy, 76, 589-599.

Davis, S.B.; Price, T.J.; Wetzstein, M.E.; Rieger, M.W. (1997) "Reducing Yield Variation in Peach Orchards by Geographic Scattering", American Journal of Agricultural Economics, 79, 1119-1126.

Djokoto, J.G.; Afari-Sefa, V.; Addo-Quaye, A. (2017) "Vegetable diversification in cocoa-based farming systems Ghana", Agriculture \& Food Security, 6, 1, article 6.

Feng, X.; Hayes, D. (2016) "Diversifying systemic risk in agriculture", Agricultural Finance Review, 76, 4, 512-531.

Krueger, A.M.; Salin, V.; Gray, A.W. (2002) "Geographic Diversification Strategy and the Implications of Global Market Integration in Table Grapes”, Agribusiness, 18, 1, 8199.

Larsen, R.; Leatham, D.; Sukcharoen, K. (2015) "Geographical diversification in wheat farming: a copula-based CVaR framework", Agricultural Finance Review, 75, 3, 368384.

Latruffe, L.; Piet, L. (2014) "Does land fragmentation affect farm performance? A case study from Brittany, France", Agricultural Systems, 129, 68-80.

Lu, H.; Xie, H.; He, Y.; Wu, Z.; Zhang, X. (2018) "Assessing the impacts of land fragmentation and plot size on yields and costs: A translog production model and cost function approach". Agricultural Systems, 161, 81-88.

Meynard, J.-M.; Charrier, F.; Fares, M.; Le Bail, M.; Magrini, M.-B.; Charlier, A.; Messéan, A. (2018) "Socio-technical lock-in hinders crop diversification in France", Agronomy for Sustainable Development, 38, 54.

Morrison Paul, C.J.; Nehring, R. (2005) "Product diversification, production systems, and economic performance in U.S. agricultural production", Journal of Econometrics, $126,525-548$.

Nartea, G.V.; Barry, P.J. (1994) "Risk Efficiency and Cost Effects of Geographic Diversification", Review of Agricultural Economics, 16, 3, 341-351. 
Navarrete, M.; Dupré, L.; Lamine, C. (2015) “Crop management, labour organization, and marketing: three key issues for improving sustainability in organic vegetable farming” International Journal of Agricultural Sustainability, 13, 3, 257-274.

Nikolova, M.; Linkova, M. (2011) "Risk diversification in the agricultural sector in Bulgaria”, Amfiteatru Economic, 13, 29, 305-320.

Nkurunziza, L.; Chongtham, I.R.; Watson, C.A.; Marstorp, H.; Öborn, I.; Bergkvist, G.; Bengtsson, J. (2017) "Understanding effects of multiple farm management practices on barley performance" European Journal of Agronomy, 90, 43-52.

Ogundari, K. (2013) "Crop diversification and technical efficiency in food crop production", International Journal of Social Economics, 40, 3, 267-287.

Pacín, F.; Oesterheld, M. (2014) "In-farm diversity stabilizes return on capital in Argentine agro-ecosystems", Agricultural Systems, 124, 51-59.

Schroth, G.; Ruf, F. (2014) "Farmer strategies for tree crop diversification in the humid tropics. A review" Agronomy for Sustainable Development, 34, 1, 139-154.

Shannon, C.E.; Weaver, W. (1949) The Mathematical Theory of Communication. University of Illinois Press, Urbana.

Shaxson, L.; Tauer, L.W. (1992) "Intercropping and diversity: An economic analysis of cropping patterns on smallholder farms in Malawi”, Experimental Agriculture, 28, 211228.

Tadesse, D.; Blank, S.C. (2003) "Cultivar diversity: A neglected risk management strategy", Journal of Agricultural and Resource Economics, 28, 2, 217-232.

Weeks, W.; Popp, M.P.; Salmeron, M.; Purcell, L.C.; Gbur, E.E.; Bourland, F.M.; et al. (2016) "Diversifying soybean production risk using maturity group and planting date choices" Agronomy Journal, 108, 5, 1917-1929.

Wezel, A.; Casagrande, M.; Celette, F.; Vian, J.-F.; Ferrer, A.; Peigné, J. (2014) "Agroecological practices for sustainable agriculture. A review" Agronomy for Sustainable Development, 34, 1, 1-20.

Yang, L.; Liu, M.; Min, Q.; Li, W. (2018) "Specialization or diversification? The situation and transition of households' livelihood in agricultural heritage systems" International Journal of Agricultural Sustainability, 16, 6, 455-471. 


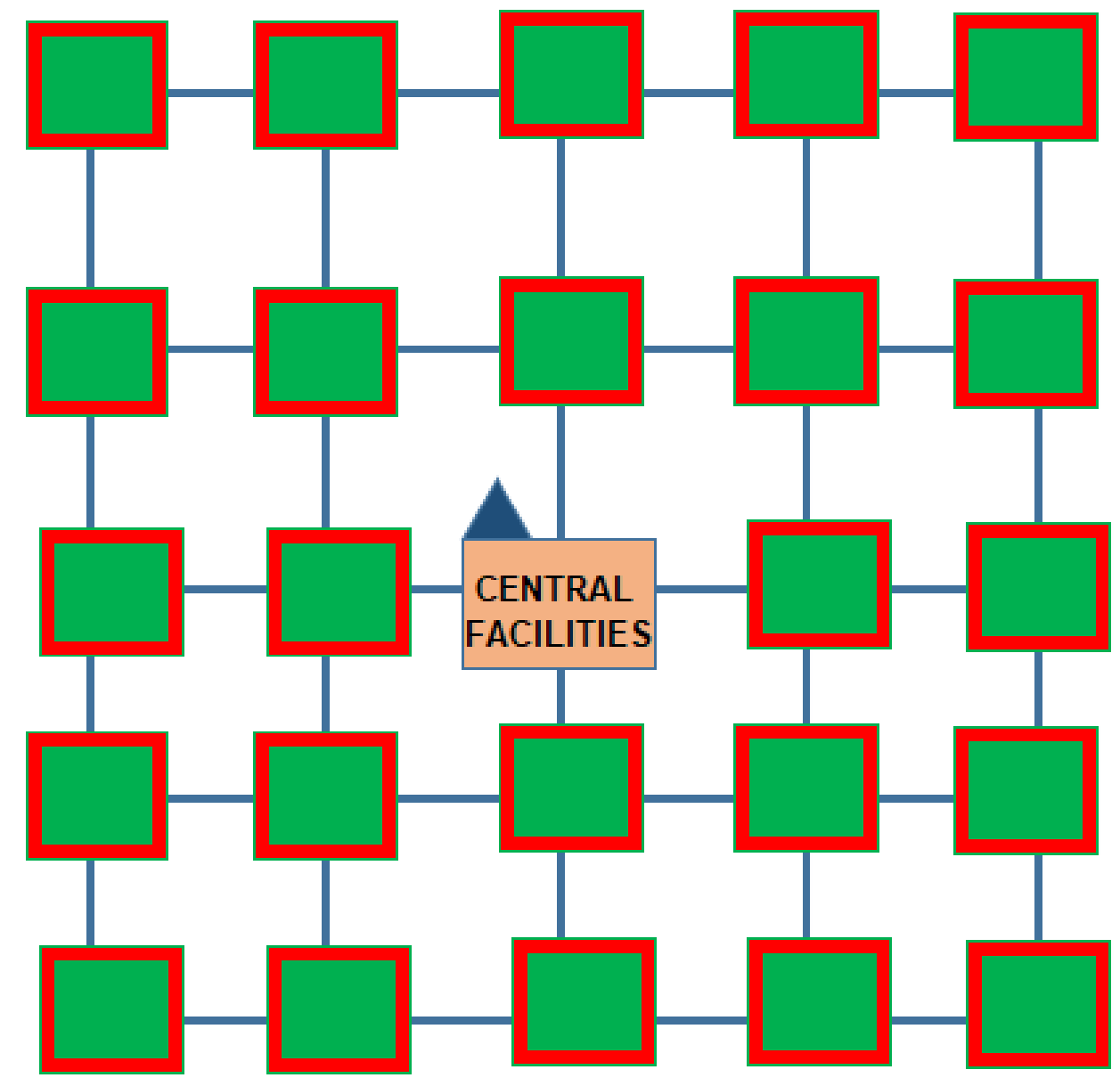

Figure 1. Layout of the net of 24 available plots considered in the experimental framework 

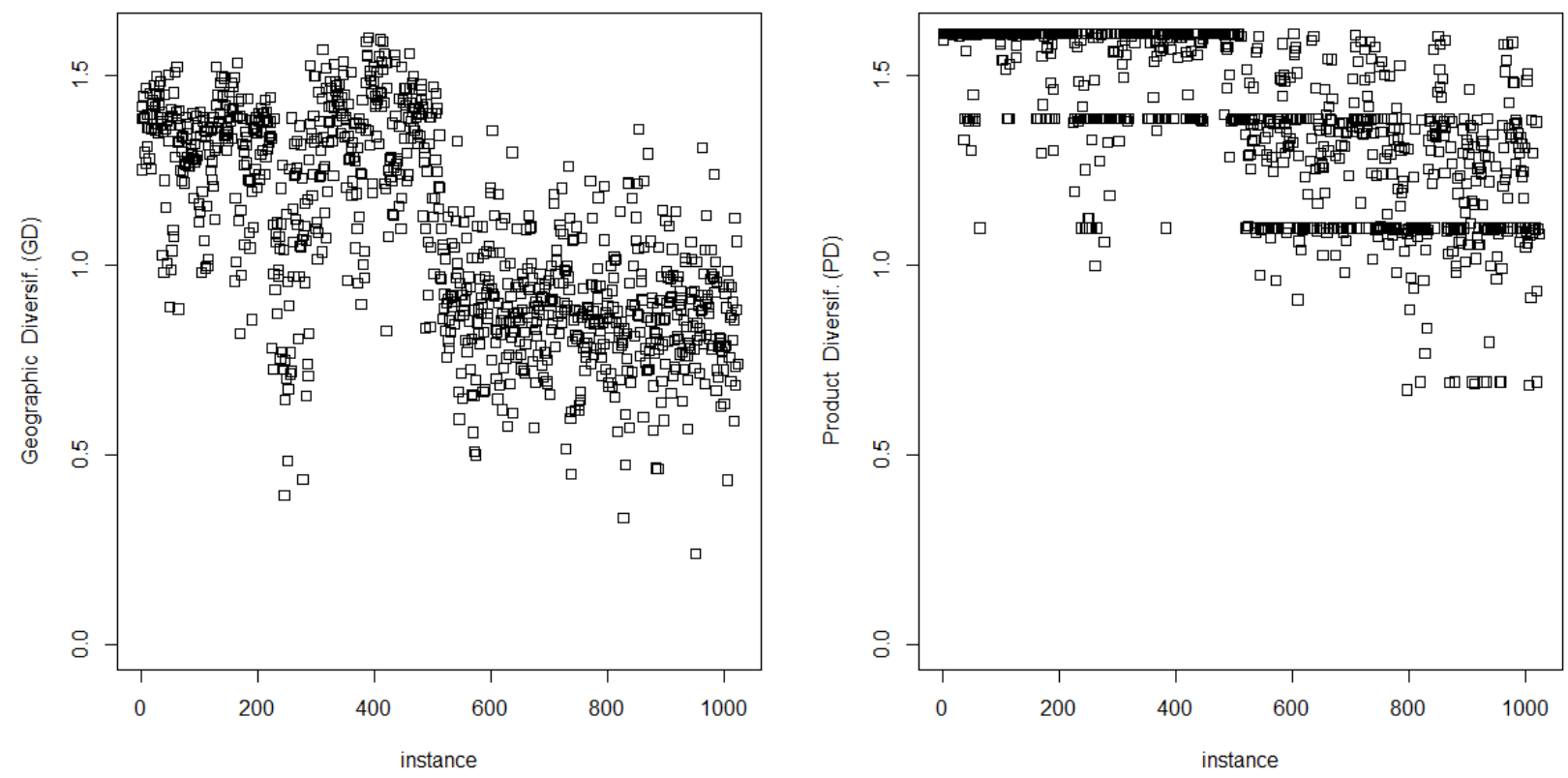

Figure 2. Geographic and Product diversification measures for each of the 1024 instances in the experimental framework 

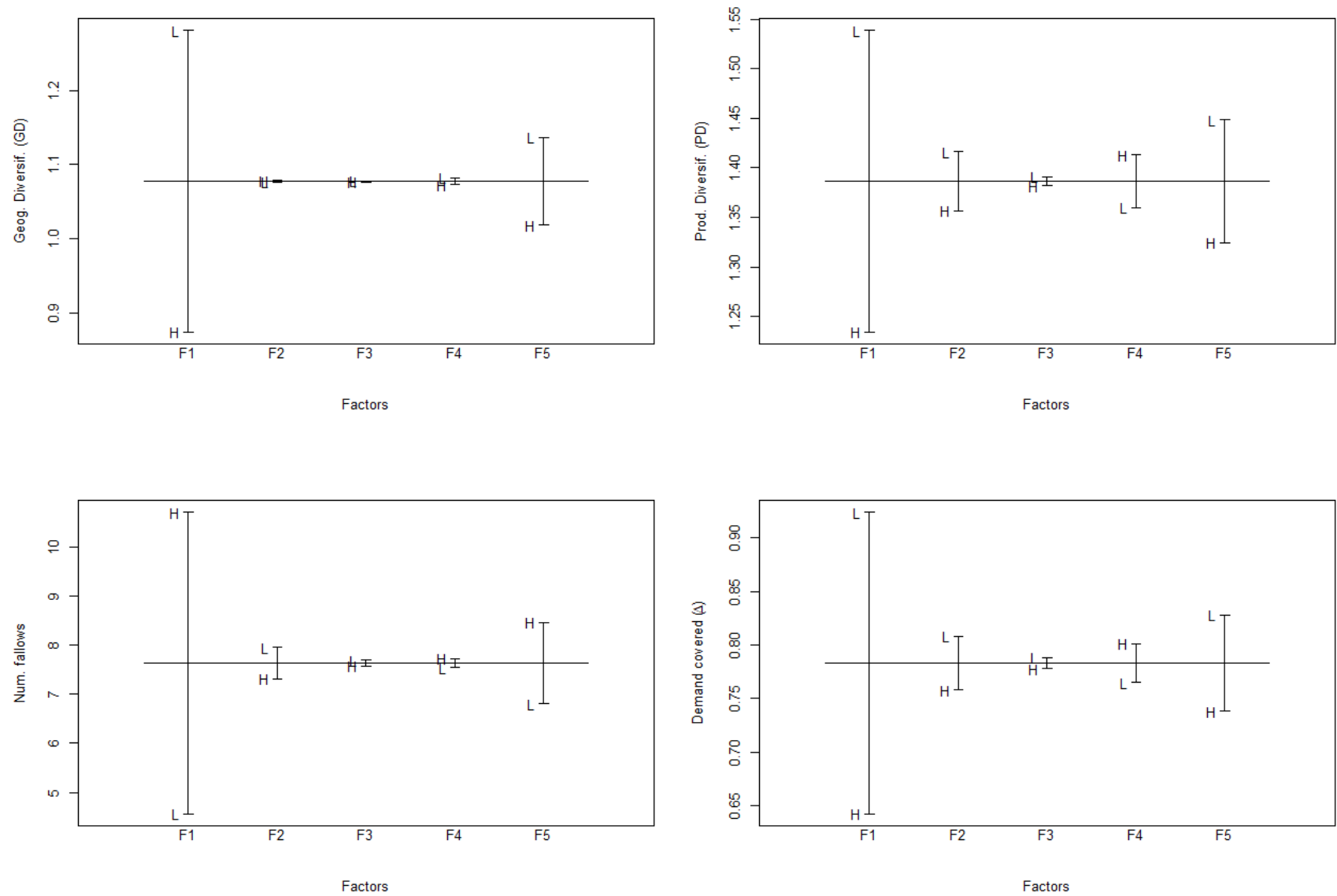

Figure 3. Average values for each factor level for the different metrics (F1: distance between plots; F2: general level of spoilage; F3: spoilage variability among plots; F4: plot yield; F5: variability of selling prices) 

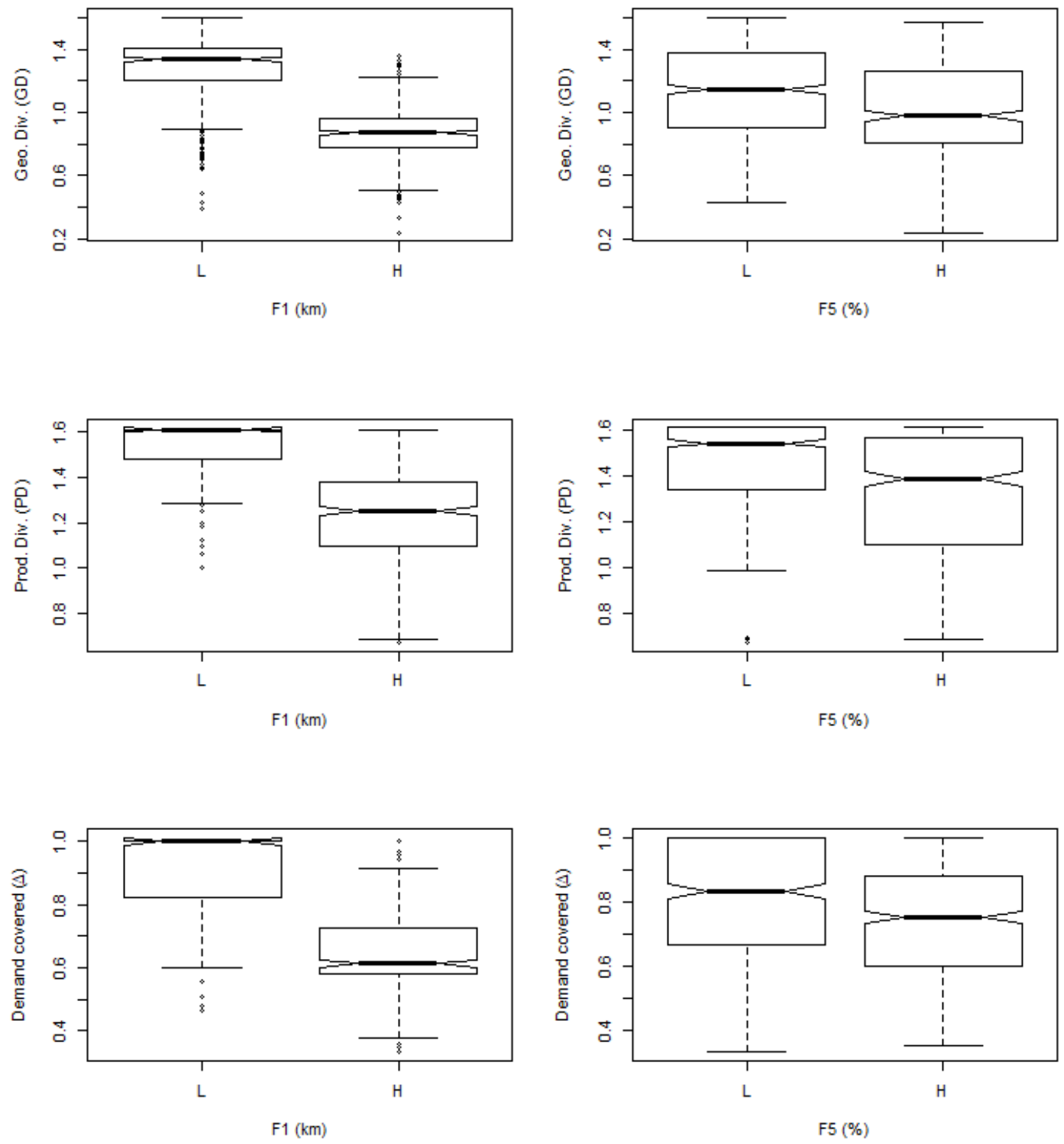

Figure 4. Box-plots for factors F1 (distance between plots) and F5 (variability in the selling prices) 


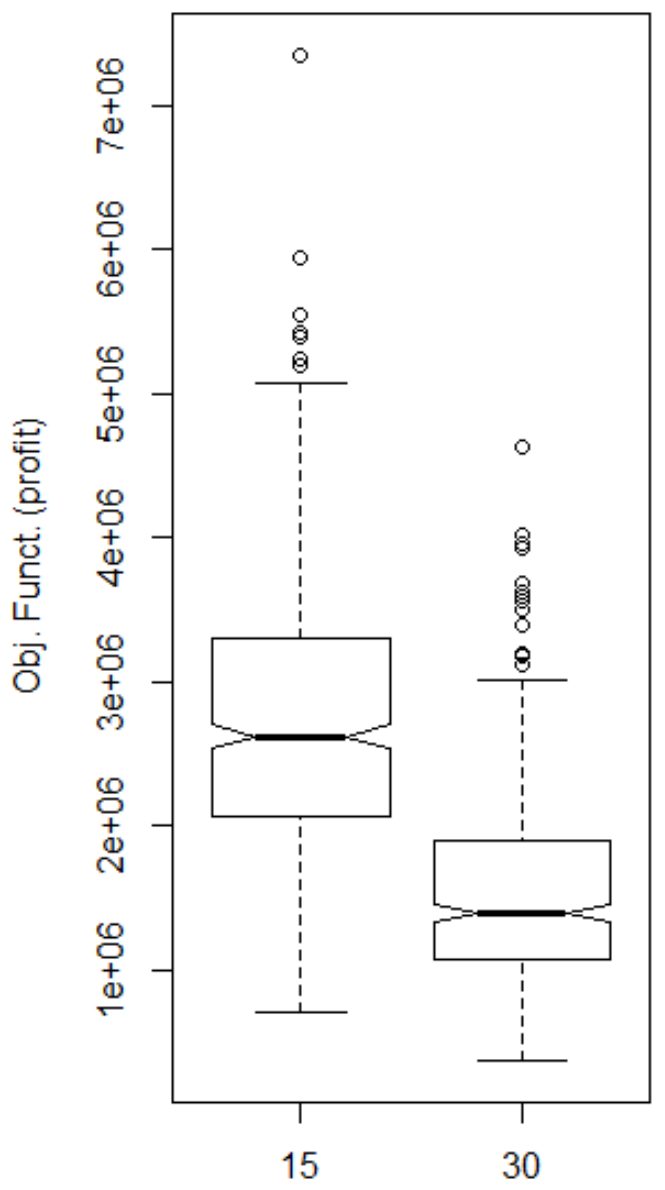

$\mathrm{F} 1(\mathrm{~km})$

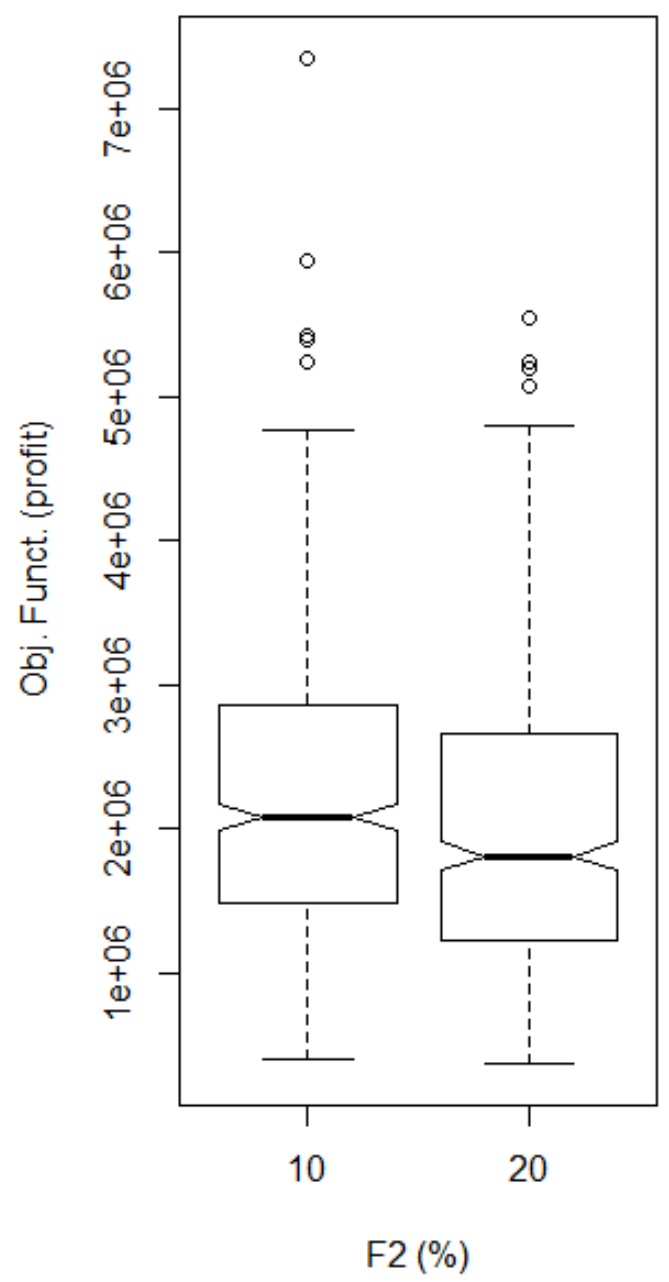

Figure 5. Box-plot for the values of the objective function (profit) corresponding to the two only significant factors (distance between plots and spoilage percentage) 

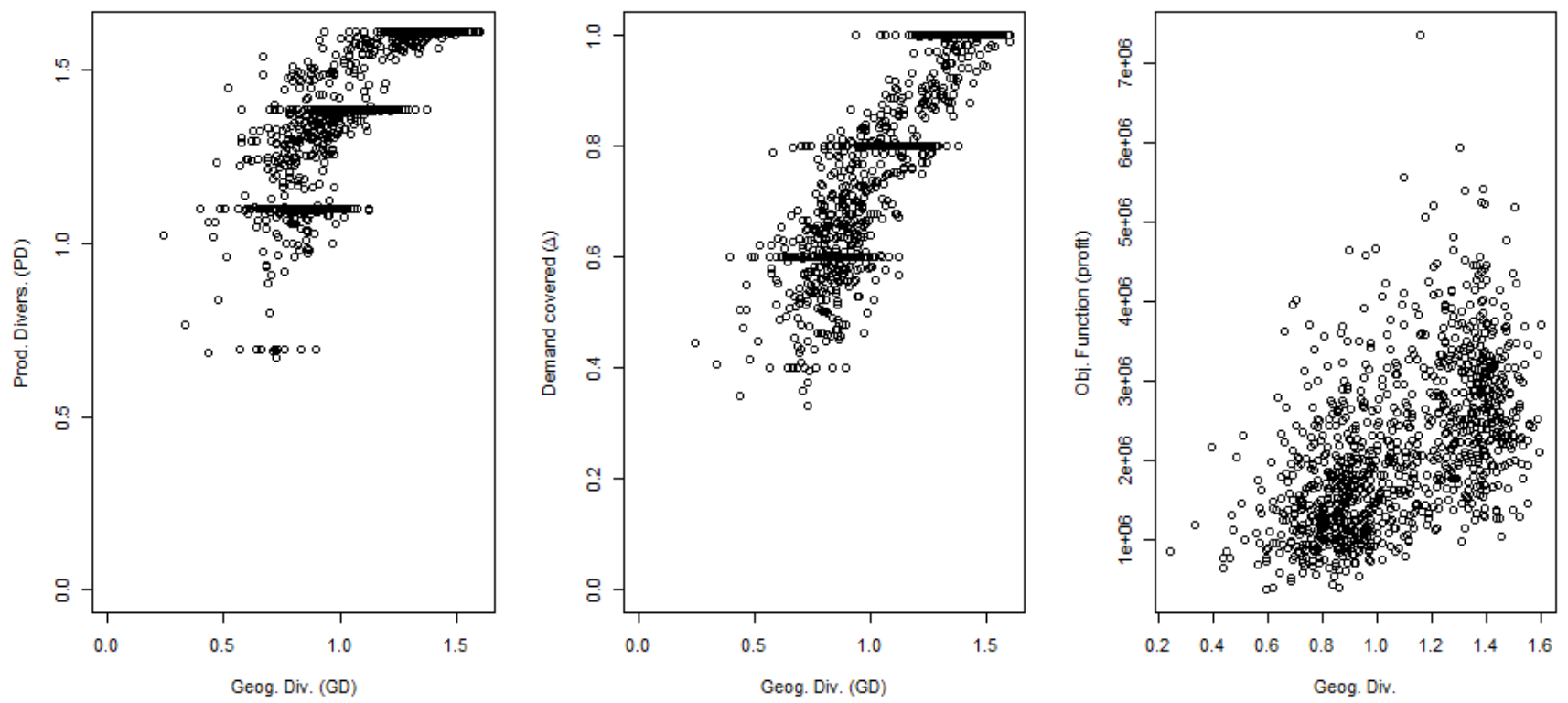

Figure 6. Relationship between Geographic diversification and Product diversification, percentage of demand covered $(\Delta)$ and profit of the crop plans. 
Table 1. Indication of whether the average value for each level of each factor is above $(\uparrow)$ or below $(\downarrow)$ the global average value of each factor, for each type of diversification.

\begin{tabular}{|c|c|c|c|c|c|c|c|c|c|c|}
\hline & \multicolumn{2}{|c|}{ F1 } & \multicolumn{2}{|c|}{ F2 } & \multicolumn{2}{|c|}{ F3 } & \multicolumn{2}{|c|}{ F4 } & \multicolumn{2}{|c|}{ F5 } \\
\hline & $\mathrm{L}$ & $\mathrm{H}$ & $\mathrm{L}$ & $\mathrm{H}$ & $\mathrm{L}$ & $\mathrm{H}$ & L & $\mathrm{H}$ & $\mathrm{L}$ & $\mathrm{H}$ \\
\hline GD & 个 & $\downarrow$ & $\downarrow$ & $\uparrow$ & $\uparrow$ & $\downarrow$ & $\uparrow$ & $\downarrow$ & 个 & $\downarrow$ \\
\hline PD & 个 & $\downarrow$ & $\uparrow$ & $\downarrow$ & $\uparrow$ & $\downarrow$ & $\downarrow$ & $\uparrow$ & 个 & $\downarrow$ \\
\hline
\end{tabular}

